\title{
Venous and arterial changes in pulmonary veno-occlusive disease, mitral stenosis and fibrosing mediastinitis
}

\author{
I. Chazova*, I. Robbins*, J. Loyd*, J. Newman*, V. Tapson*, V. Zhdaov*, B. Meyrick
}

\begin{abstract}
Venous and arterial changes in pulmonary veno-occlusive disease, mitral stenosis and fibrosing mediastinitis. I. Chazova, I. Robbins, J. Loyd, J. Newman, V. Tapson, V. Zhdanov, B. Meyrick. (C) ERS Journals Ltd 2000.

ABSTRACT: The pathogenesis of pulmonary veno-occlusive disease (PVOD) is not known. The diagnosis of PVOD frequently relies on its histological changes since it is often difficult to distinguish clinically from primary pulmonary hypertension.

This study carried out a systematic analysis of the pulmonary venous and arterial remodelling that occurs in PVOD $(n=5)$ and compared these changes to two other diseases affecting the pulmonary veins, mitral stenosis (MS; $n=6)$ and fibrosing mediastinitis (FM; $\mathbf{n = 2}$ ), using established morphometric techniques.

In PVOD, pronounced intimal and adventitial thickening were noted in veins of all sizes and arterialization of veins $>\mathbf{5 0} \mu \mathrm{m}$ external diameter was found. Similar changes were evident in the arterial wall, but intimal thickening was less severe than in the veins and medial thickening was more pronounced in arteries $<\mathbf{3 0 0} \mu \mathrm{m}$ external diameter. Eccentric intimal fibrosis of the veins was also noted for the first time in PVOD, although this feature occurred less frequently (approximately one third) than in MS. Less pronounced structural remodelling was also encountered in the veins in cases of MS and FM. The severity of the venous changes in PVOD may aid its diagnosis and lend insight into its pathogenesis. However, the similarity of the vascular changes in each form of venous hypertension also suggests that pathology alone may not always differentiate between these disease states.

The similarity of the vascular changes in the three forms of venous hypertension suggests that, as in pulmonary artery hypertension, pressure, per se, is one of the triggers to vascular remodelling.

Eur Respir J 2000; 15: 116-122.
\end{abstract}

\author{
*Division of Allergy, and Pulmonary \\ Critical Care Medicine and ${ }^{+}$Dept of \\ Pathology, Vanderbilt University Medical \\ Center, Nashville, TN, USA. ${ }^{\star}$ Cardiology \\ Research Complex, Moscow, Russia. \\ "Pulmonary Medicine, Duke University \\ Medical Center, Durham, NC, USA. \\ Correspondence: B. Meyrick \\ Center for Lung Research \\ Vanderbirlt University Medical Center \\ Nashville, TN 37232-2650
}
MCN, T 1217
USA
Fax: 6153437448
Keywords: Adventitia
intimal
media
pathology

Received: December 71998

Accepted after revision June 91999

This work was supported by grants from the National Heart Lung and Blood Institute, HL 48536 and HL 48164.
Pulmonary veno-occlusive disease (PVOD) is a rare cause of pulmonary hypertension in which the structure of the veins is predominately affected. Clinically, PVOD is difficult to distinguish from the more common form of primary pulmonary hypertension (PPH). It is unclear whether PVOD is a distinct disease or a subset of PPH sharing a similar pathogenesis but targeting different segments of the pulmonary circulation. Since the first description by Hora [1], $\sim 150$ cases of PVOD have been described [213]. The aetiology of PVOD is unknown but has been observed in patients following bone marrow transplantation, using oral contraceptives, receiving treatment with chemotherapeutic agents and recently in a patient with human immunodeficiency virus (HIV) infection [14-21]. Familial cases also have been described in siblings from two families [22, 23].

While the pathogenesis of PVOD is uncertain, characteristic histological changes are found in the pulmonary veins. These include occlusion and recanalization of the lumen, and muscularization and intimal fibrosis of small pulmonary veins. Thrombosis of post-capillary pulmonary vessels may also occur [3, 9, 24]. Small pulmonary arteries are also affected but the changes are less severe than those seen in the venous circulation [25-27]. Morphometric analysis of the vascular changes in PVOD has been reported in only a few cases [23, 28, 29].
To further elucidate the pathogenesis of PVOD, the present study defines the severity of the pulmonary venous and arterial changes using systematic, statistical morphometric techniques and compares each of these changes to those of two other diseases affecting the pulmonary veins, i.e., mitral stenosis (MS), a disease that is sometimes confused clinically with PVOD, and pulmonary venous obstruction due to fibrosing mediastinitis (FM). Particular emphasis was placed on the severity and frequency of each change related to venous and artery size, and to the type of intimal lesion.

\section{Materials and methods}

Lung samples from five patients (four females and one male), age $23-57$ yrs, pulmonary artery pressure $(P$ pa $) 63 \pm$ $10 \mathrm{mmHg}$, pulmonary capillary wedge pressure (PCWP) $9 \pm 1 \mathrm{mmHg}$, mean \pm SEM with the pathological diagnosis of PVOD, six patients with the clinical diagnosis of MS with pulmonary hypertension (four females and two males, age 32-54 yrs, duration of disease 5-12 yrs) and two cases of documented FM (one male and one female, age 36 and 26 yrs, $P$ pa $85 / 35$ and $73 / 25 \mathrm{mmHg}$, respectively) were examined. Lung tissue was obtained at autopsy in four cases. One further lung was taken at transplant; lung biopsy tissue 
was also taken from this patient 6 months prior to transplantation. Controls consisted of five autopsy cases without cardiac or pulmonary disease (age 17-50 yrs). All lungs were distended by way of the trachea and fixed in $10 \%$ formol-saline. All lungs appeared inflated by light microscopy although the degree of inflation was difficult to standardize since lung tissue was collected from three centres over a number of years. Between two and five blocks from each case were processed for routine light microscopy. Sections $(5 \mu \mathrm{m})$ were stained with haematoxylin and eosin, Masson's pentachrome, or Verhoeff's elastin stain followed by Van Gieson.

The clinical diagnosis of PVOD was made after thorough evaluation to exclude secondary causes of pulmonary hypertension. This included physical examination, chest radiography, electrocardiogram (ECG), echocardiography, pulmonary function testing, lung perfusion scan and right heart catheterization. Pulmonary artery pressure was increased in all cases with elevation of pulmonary wedge pressure in one case (mean $P$ pa $62 \mathrm{mmHg}$, mean PCWP $14 \mathrm{mmHg}$ ). Perfusion lung scans showed nonhomogeneous mottling in each case but no significant (subsegmental or larger) perfusion defects were found. Chest radiographs revealed Kerly B-lines in two patients. History and serological studies did not suggest collagen vascular disease or HIV as a cause of pulmonary hypertension.

Diagnosis of MS was based on a thorough clinical examination, chest radiography, ECG, and confirmed by echocardiography. FM with obstruction of large pulmonary veins was diagnosed by contrasted computed tomography $(\mathrm{CT})$ scan and pulmonary angiographic studies and was later confirmed at autopsy.

\section{Morphometric assessment of pulmonary arteries and veins}

As previously described [30], pulmonary veins were distinguished from pulmonary arteries on the basis of position and structure. Pulmonary veins were found at the edge of acini or midway between two arteries, whereas pulmonary arteries were seen mainly in association with airways. Pulmonary arteries generally had two or more elastic laminae defining the medial coat, while pulmonary veins had only a single lamina, unless "arterialization" of the veins had occurred. Using an eye-piece reticle, external diameter of pulmonary veins with a single elastic lamina was measured as the shortest luminal distance from the external edge of the single elastic lamina on one side to that on the other. Only those profiles that were cut in true cross section or in oblique section in which the length of the profile was less than twice external diameter were included. Intimal thickness was measured from the luminal edge of the single elastic lamina to the luminal surface and the adventitial thickness from the external edge of the single elastic lamina to include the collagenous perivascular sheath and smooth muscle cells when present. These measurements were made at the same site as external diameter.

Medial, intimal and adventitial thickness of arteries and of arterialized veins with two elastic laminae were measured at the same site as external diameter. Adventitial thickness of the veins and arteries was measured from the luminal edge of the external elastic lamina to the edge of the collagen-containing vascular sheath. Medial thickness for arterial and arterialized vessels was measured between and including the internal and external elastic lamina. Intimal thickness was measured from the luminal edge of the internal elastic lamina to the luminal surface. The thickness of each vessel coat for both veins and arteries was then related to external diameter as follows percentage intimal thickness $=2 \times$ intimal thickness/external diameter $\times 100 ; \%$ medial thickness $=2 \times$ medial thickness/ external diameter $\times 100$; percentage adventitial thickness $=2 \times$ adventitial thickness/external diameter $\times 100$. At least 40 veins and 40 arteries were examined from each patient.

For every artery and vein examined, the presence of concentric fibrosis, eccentric intimal thickening, obliteration and recanalization was recorded. Pulmonary vessels were grouped according to the following external diameters: $25-50 ; 51-100,101-200 ; 201-300$ and $301-1,000$ $\mu \mathrm{m}$ for each patient. Structural changes, i.e., per cent intimal, medial and adventitial thickness of arteries and veins were calculated for each size range.

\section{Statistics}

The mean \pm SEM was calculated for each measured variable in the PVOD and MS groups of patients. Calculations of per cent adventitial, medial, and intimal thickness for arteries and veins and per cent of total intimal lesions included data from patients with PVOD, patients with MS, patients with FM and controls. Data were compared using the unpaired Student's t-test. A p-value $<0.05$ was taken as significant.

\section{Results}

\section{Pulmonary veno-occlusive disease}

Intimal and adventitial thickening was significantly elevated in all sized pulmonary veins when compared to controls (figs. 1a, 2a and c). Intimal lesions included concentric fibrosis $(29.8 \pm 7.3 \%$ of veins examined) often with a cellular component external to the fibrotic lesion (fig. $1 b)$, eccentric intimal thickening $(16.6 \pm 6.0 \%)$, occlusion $(11.5 \pm 1.6 \%)$, and recanalization $(13.2 \pm 8.9 \%)$ (fig. $1 \mathrm{a}-\mathrm{d})$. Each kind of intimal lesion was found in all cases, except for recanalization (fig. 1e) which was found only in three of five cases. Concentric intimal fibrosis affected mainly the small veins $<100 \mu \mathrm{m}$ external diameter. Significant muscularization and "arterialization" of the normally nonmuscular veins was also apparent, although veins of $<50$ $\mu \mathrm{m}$ external diameter were unaffected by this process (fig. 2b). Increased elastin fibres and reduplication of the elastic lamina were frequent findings at the medial/ adventitial border (fig. 1a and c). Adventitial thickening was mainly the result of increased collagen and elastin deposition (fig. 1a).

A significant increase in intimal, medial and adventitial thickness was also found for arteries in each size range when compared to controls (figs. 1f and 3). The per cent increase in arterial intimal thickness was less pronounced, approximately one third that seen in veins (figs. $2 \mathrm{a}$ and $3 \mathrm{a}$ ). Concentric intimal thickening was found in four of the 

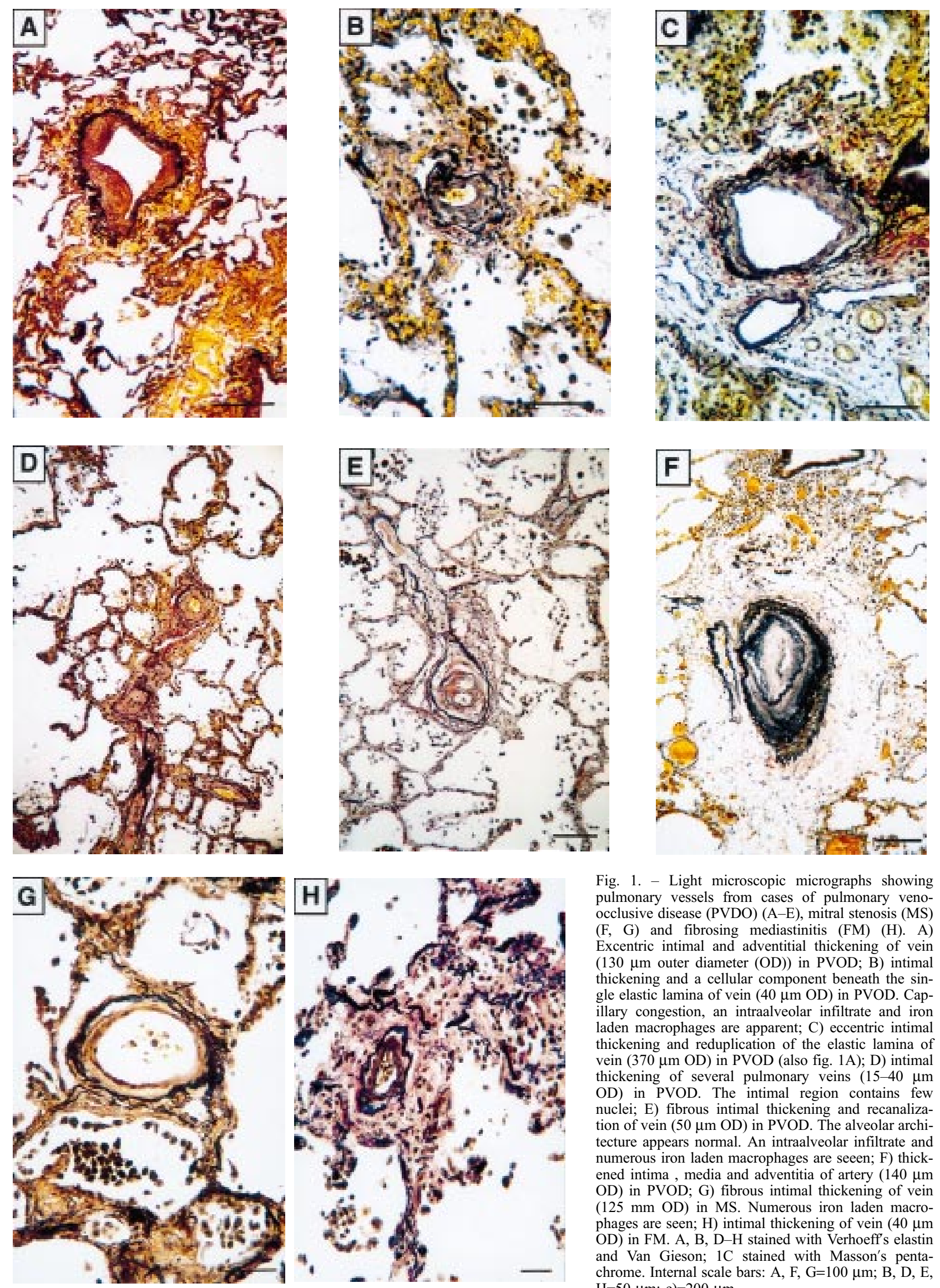

Fig. 1. - Light microscopic micrographs showing pulmonary vessels from cases of pulmonary venoocclusive disease (PVDO) (A-E), mitral stenosis (MS) $(\mathrm{F}, \mathrm{G})$ and fibrosing mediastinitis $(\mathrm{FM})(\mathrm{H})$. A) Excentric intimal and adventitial thickening of vein $(130 \mu \mathrm{m}$ outer diameter (OD)) in PVOD; B) intimal thickening and a cellular component beneath the single elastic lamina of vein $(40 \mu \mathrm{m}$ OD) in PVOD. Capillary congestion, an intraalveolar infiltrate and iron laden macrophages are apparent; C) eccentric intimal thickening and reduplication of the elastic lamina of vein (370 $\mu \mathrm{m}$ OD) in PVOD (also fig. 1A); D) intimal thickening of several pulmonary veins $(15-40 \mu \mathrm{m}$ OD) in PVOD. The intimal region contains few nuclei; E) fibrous intimal thickening and recanalization of vein (50 $\mathrm{m}$ OD) in PVOD. The alveolar architecture appears normal. An intraalveolar infiltrate and numerous iron laden macrophages are seeen; F) thickened intima, media and adventitia of artery $(140 \mu \mathrm{m}$ OD) in PVOD; G) fibrous intimal thickening of vein $(125 \mathrm{~mm} \mathrm{OD})$ in MS. Numerous iron laden macrophages are seen; $H)$ intimal thickening of vein $(40 \mu \mathrm{m}$ OD) in FM. A, B, D-H stained with Verhoeff's elastin and Van Gieson; 1C stained with Masson's pentachrome. Internal scale bars: A, F, G=100 $\mu \mathrm{m} ; \mathrm{B}, \mathrm{D}, \mathrm{E}$, $\mathrm{H}=50 \mu \mathrm{m} ; \mathrm{c})=200 \mu \mathrm{m}$. 

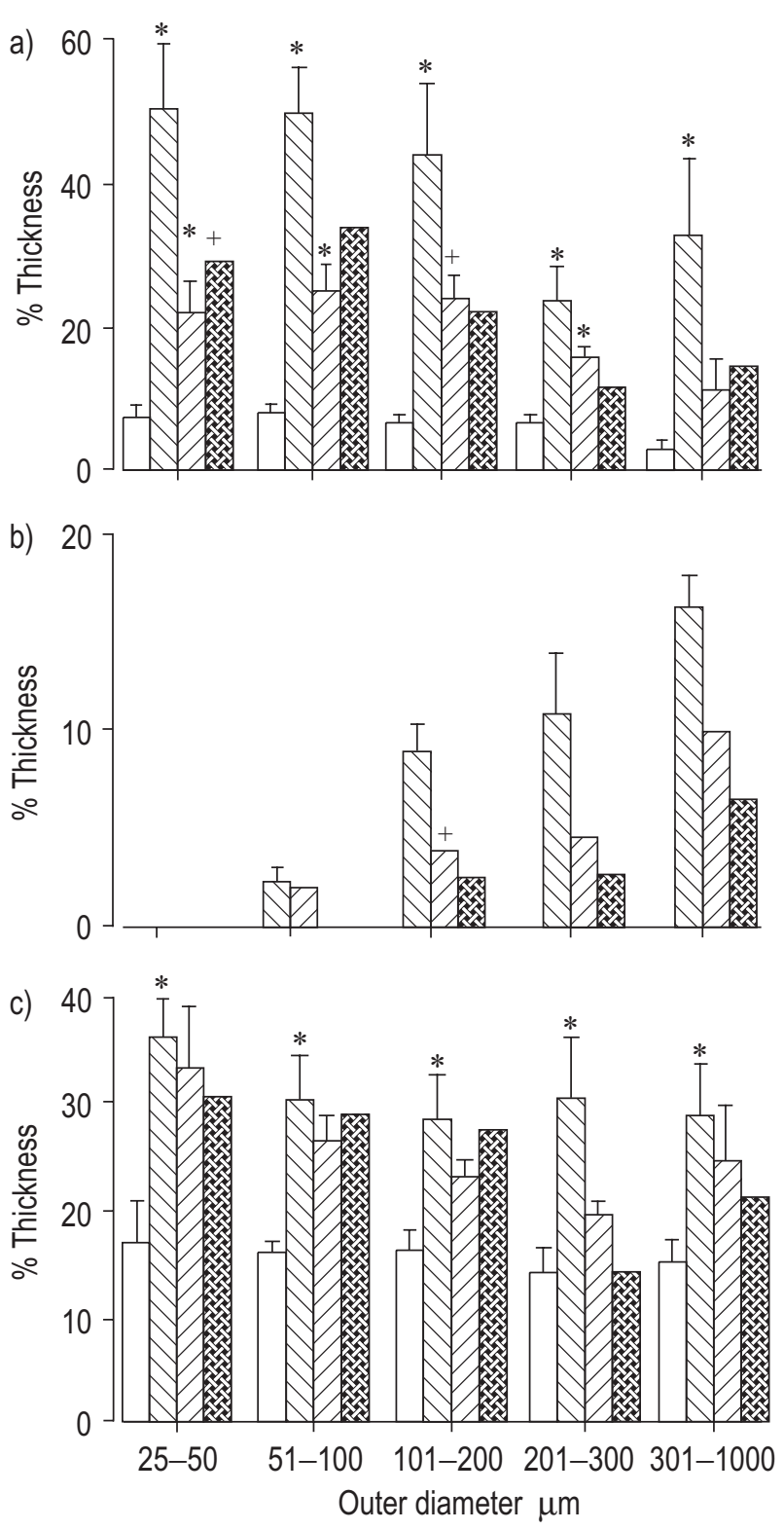

Fig. 2. - Per cent venous intimal (a), medial (b) and adventitial thickness (c) from control $(\square \mathrm{n}=5$ ), pulmonary veno-occlusive disease (PVOD) $(\mathbb{\mathbb { N }}=5)$ mitral stenosis (MS) $(\mathbb{Z} \mathrm{n}=6)$ and fibrosing mediatinitis (FM), ( $\mathrm{n}=2)$ patients. Data are mean \pm SEM. ${ }^{*}: \mathrm{p}<0.05$ compared to controls; ${ }^{+}$: $\mathrm{p}<0.05$ compared to PVOD.

five cases but affected only $8.2 \pm 3.5 \%$ of the arteries examined, less than a quarter of the number of veins showing this change. Occasional arteries with either eccentric intimal thickening or occlusion were found in one case. Recanalization of arteries was not encountered. Medial thickening was more pronounced than in the veins (figs. $2 \mathrm{~b}$ and $3 \mathrm{~b}$ ) and muscularization of small, normally nonmuscular arteries $(25-50 \mu \mathrm{m}$ external diameter) was a feature. Adventitial thickening was similar in severity in arteries and veins, although it was frequently less collagenous than that of the veins. While most of the alveolar region was normal in architecture (fig. $1 \mathrm{~b}$ and e), focal areas of fibrosis and inflammation were evident in three of the five cases examined. Haemorrhage, iron laden alveolar macrophages (fig. $1 \mathrm{~b}$ and e), dilated lymphatics
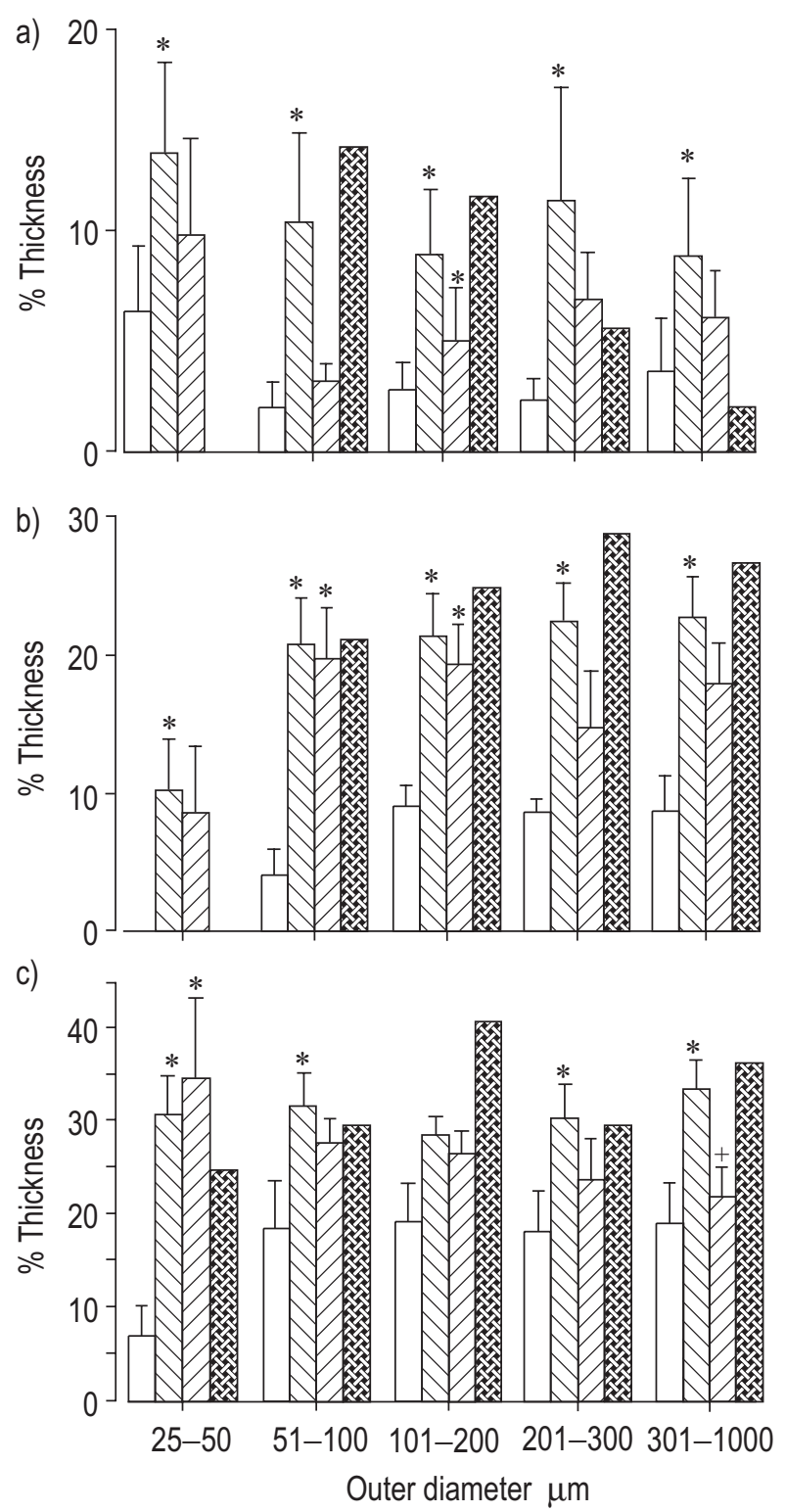

Fig. 3. - Per cent arterial intimal (a), medial (b) and adventitial thickness (c) from control ( $\square$ n=5), pulmonary veno-occlusive disease (PVOD) $(\mathbb{\mathbb { n }}=5)$, mitral stenosis (MS) $(\mathbb{Z} \mathrm{n}=6)$ and fibrosing mediatinitis (FM) ( $\mathrm{n}=2)$ patients. Data are mean \pm SEM. ${ }^{*}: \mathrm{p}<0.05$ compared to controls. ${ }^{+}$: $\mathrm{p}<0.05$ compared to PVOD.

and focal areas of congestion (fig. 1b) were often encountered.

In the one case of PVOD where a biopsy and posttransplant tissue was available for comparison, progression of the intimal venous changes and arterialization (per cent medial thickness) was apparent over a 6 month period (table 1). At the time of transplantation, intimal thickness of the pulmonary veins in each size range had increased by $40-100 \%$ and medial thickness had increased 3-7 times that seen in biopsy tissue; adventitial thickness was similar at biopsy and transplantation (table 1). The number of intimal lesions also progressed with time; the per cent of total veins with concentric fibrosis increased 14 $20 \%$, eccentric intimal thickening $8-17 \%$, and occlusion $4-12 \%$. Recanalization was occasionally found in the transplant tissue and was only a feature of the smallest 
Table 1. - Progression of per cent intimal, medial and adventitial thickness in lung biopsy to transplant tissue

\begin{tabular}{|c|c|c|c|c|c|c|c|c|c|c|c|c|c|c|c|}
\hline \multirow[b]{3}{*}{ Structure } & \multicolumn{15}{|c|}{ External diameter $\mu \mathrm{m}$} \\
\hline & \multicolumn{3}{|c|}{$<50$} & \multicolumn{3}{|c|}{$51-100$} & \multicolumn{3}{|c|}{$101-200$} & \multicolumn{3}{|c|}{$201-300$} & \multicolumn{3}{|c|}{$301-1000$} \\
\hline & I & M & A & I & M & A & I & M & A & I & M & A & I & M & A \\
\hline \multicolumn{16}{|l|}{ Veins } \\
\hline Biopsy & 51 & 0 & 38 & 35 & 0 & 30 & 13 & 2 & 28 & 9 & 6 & 31 & 6 & 6 & 17 \\
\hline Transplant & 70 & 0 & 34 & 42 & 4 & 26 & 24 & 14 & 27 & 17 & 22 & 30 & 10 & 30 & 25 \\
\hline \multicolumn{16}{|l|}{ Arteries } \\
\hline Biopsy & 16 & 17 & 37 & 7 & 19 & 34 & 4 & 21 & 25 & 0 & 17 & 17 & 4 & 23 & 28 \\
\hline Transplant & 22 & 20 & 31 & 7 & 30 & 35 & 5 & 26 & 28 & 5 & 29 & 37 & 6 & 23 & 28 \\
\hline
\end{tabular}

I: per cent intimal thickness; M: per cent medial thickness; A: per cent adventitial thickness.

veins. In general, the per cent of total arteries with intimal and adventitial thickening was similar at both time points, but medial thickening progressed in arteries of 51-300 $\mu \mathrm{m}$ external diameter (table 1). Concentric thickening was the only intimal lesion encountered in the arteries and occurred, at both time points, only in arteries of $<50 \mu \mathrm{m}$ external diameter.

\section{Mitral stenosis}

An increased thickness of the intimal, medial and adventitial layers was found for veins of each external diameter examined when compared to controls but was only significant for the intima and media (figs. 1a, 2a and c). For veins of each size range, intimal and medial thickening in MS was less severe than that found in PVOD. In all patients with MS, venous intimal thickening was predominantly due to concentric fibrosis $(45.9 \pm 5.5 \%$ of all veins examined) (fig. 1a), a value that was $\sim 5$ times that found in PVOD. Eccentric intimal fibrosis, occlusion and recanalization of veins $(2.2 \pm 1.4,0.6 \pm 0.5$ and $0.6 \pm$ $0.5 \%$, respectively) were rarely exhibited in MS and were significantly less frequent than in PVOD. As with PVOD, arterialization was not observed in the walls of the smallest veins $(25-50 \mu \mathrm{m})$ (fig. $2 \mathrm{~b})$. In veins $>50 \mu \mathrm{m}$ external diameter, increased medial thickness became more pronounced as external diameter increased. Adventitial thickening was similar in severity in MS and PVOD but collagen accumulation was less pronounced.

Pulmonary arterial remodelling also occurred in MS. Medial and adventitial thickness was increased when compared to controls (fig. $3 \mathrm{~b}$ and c). Specifically, medial thickness of arteries 51-200 $\mu \mathrm{m}$ and adventitial thickness of arteries $25-50 \mu \mathrm{m}$ external diameter were significantly greater than control values. The severity of the adventitial and medial thickening in MS was similar to that seen in PVOD except for arteries of 301-1,000 $\mu \mathrm{m}$ external diameter which showed significantly less adventitial change. Abnormal appearance of muscle in the walls of smaller and more peripheral arteries was evident in all cases of MS evaluated and, in general, was comparable in severity to that noted in PVOD. Only a small number of arteries in three of five cases showed concentric fibrosis $(3.3 \pm 2.1 \%)$ and this change was only apparent in those vessels $<50 \mu \mathrm{m}$ external diameter. Other intimal lesions were not identified. Patchy fibrotic changes, increased elastin accumulation, dilated lymphatics, congestion, haemorrhage and iron laden macrophages were apparent in all cases examined.

\section{Fibrosing mediastinitis}

In the two cases of FM examined the venous changes were, in general, similar in severity to those of MS (figs. 1h and 2). Arterial intimal thickness tended to be greater in FM for arteries 25-200 $\mu \mathrm{m}$ external diameter than in MS and the values were more similar to those in PVOD (figs. 2 and 3). The severity of medial thickening in FM was similar to that in PVOD for arteries 51-200 $\mu \mathrm{m}$ external diameter but was strikingly higher for arteries $25-51 \mu \mathrm{m}$ external diameter. Adventitial thickness, like that of the veins, was similar in severity to that of both MS and PVOD (figs. 2c and 3c). Fibrosis, dilated lymphatics, congestion, haemorrhage and iron laden macrophages were found in the lungs of both patients.

\section{Discussion}

This systematic, statistical analysis of lung vasculature from five patients with PVOD revealed severe intimal and adventitial thickening and arterialization of veins. In the one patient with PVOD where lung tissue was available at two time points over a 6-month period, marked progression of the venous changes was observed, confirming the rapid evolution of this disease. Remodelling was also apparent in pulmonary arteries, but the intimal thickening was less severe than in the veins while that of the media was more severe. Similar changes in the veins and arteries were also found in MS and FM, but the severity of the venous remodelling was most pronounced in PVOD. Prior studies of PVOD have reported varying degrees of venous medial thickness ranging from normal to strikingly increased, adventitial thickening, arterialization of veins, concentric fibrosis, venous recanalization and thrombosis $[2,3,19,23,24,28,29]$. In the arteries, medial thickening has been found to range from mild to severe with patchy areas of intimal fibrosis [23, 28, 29].

The striking and consistent intimal, medial and adventitial thickening of the venous and arterial circulation in PVOD is similar to the current findings in lungs of patients with $\mathrm{PPH}$, but in $\mathrm{PPH}$ the arterial changes were obviously more severe than those in the veins [30]. Increased intimal thickness was perhaps the most striking finding in the smaller veins in PVOD and the predominant intimal lesion was concentric fibrosis. Arterialization also occurred in veins $>51 \mu \mathrm{m}$ external diameter. Only $11-13 \%$ of the small veins exhibited evidence of thrombosis and recanalization suggesting that thickening of the intima is a primary event occurring in the absence of thrombosis. Thrombotic lesions are a recognized feature in autopsy 
samples taken from patients dying of nonpulmonary illnesses [25]. This study is the first, to the authors' knowledge, to observe venous eccentric intimal thickening as well as arterial concentric fibrosis as frequent features of PVOD. The consistency and severity of the structural changes in the pulmonary veins in this study extends the spectrum of findings from previous reports [23, 27-29].

The aetiology of PVOD is unknown. One hypothesis is that endothelial damage is the result of viral and/or respiratory infection, a history of which is frequently elicited in patients with this disease [31]. Why the pulmonary venous circulation would be specifically targeted is unclear, but perhaps implies a heightened sensitivity of the veins either to the infectious entity itself or to the host immune response. A genetic predisposition may also be an important factor, especially since two familial cases of PVOD have been described [22, 23]. The development of PVOD may require both a specific genotype and an environmental insult in order for the disease to become manifest.

The current analysis confirms that venous and arterial thickening in MS involves each layer of the wall [24-26, 32]. In contrast to the study of WAGENVOORT [32], intimal thickening was less pronounced in the arteries than veins. This discrepancy may reflect the differences in technical assessment; no statistical analysis was used in the study of WAGENVOORT [32]. The greater frequency of concentric intimal fibrosis in MS than in PVOD may reflect the longer duration of this disease process. The more extensive structural changes noted in PVOD compared to MS may reflect the different pathogenic mechanisms of PVOD and MS. Increased pulmonary venous pressures are thought to initiate the vascular alterations in MS, whereas in PVOD, an abnormality of the veins themselves is suggested to be part of the primary process, with elevations in pressure a secondary event. The finding of concentric fibrosis in PVOD and MS may represent a final common response to vascular injury that may result from vasoconstriction, pressure elevation, or in situ thrombosis either alone or in combination.

The present study also demonstrates that venous and arterial changes are often a feature of FM but the pattern of these changes is not identical to that of either PVOD or MS. The venous changes of FM were most similar to those in MS while intimal thickening of the smaller arteries was most similar to those in PVOD. Arterial intimal thickening of the smallest arteries was more severe than in either PVOD or MS. These differences in structural remodelling of the vessels are perhaps not surprising since FM may simultaneously affect both the venous and arterial circulation [33].

The impressive medial thickening of the smaller arteries compared with veins in PVOD, MS and FM may reflect the basic structural differences in the pre- and postcapillary pulmonary circulation. Arterial walls are more cellular than those of veins, and small partially and nonmuscular arteries are known to contain precursor smooth muscle cells their walls $[34,35]$. Thus, muscular hypertrophy in response to elevated pressure might be expected to be more severe in small arteries than in veins and is probably the result of the differentiation of precursor to mature smooth muscle cells. The absence of a medial layer in the smallest veins suggests that precursor smooth muscle cells are rarely a feature of their walls. The similarity of the increase in venous and arterial adventitial thickness suggests that this change may be a direct effect of increased intravascular pressure and/or the increase in collagen and elastin acting to limit vessel dilatation. This latter suggestion has also been proposed in PPH and in animal models of chronic pulmonary hypertension $[30,36,37]$.

In conclusion, in pulmonary venous hypertension due to PVOD, MS and FM, vascular remodelling occurs in both pulmonary veins and arteries. The structural changes in the veins are most prominent in PVOD compared to MS and FM, and thus may provide a morphological approach to differentiation of these conditions. In PVOD, the severity of the intimal changes in the veins, and to a lesser degree in the arteries, without evidence of widespread thrombotic lesions, suggests that endothelial perturbation may be primarily responsible for the development of this disease. However, the similarity of changes in each form of pulmonary venous hypertension suggests that pressure itself contributes to the vascular remodelling and the similarities in the structural changes may present difficulties in differentiating between the different forms of venous hypertension. Future studies involving immunohistochemical and in situ hybridization techniques to examine possible mediators of this disease are needed to better elucidate the mechanism responsible for the development of PVOD. Inclusion of control lungs from diseases such as MS and FM will be important where the structural alterations are likely to occur secondary to downstream obstruction.

\section{References}

1. Hora J. Zur histologic der klinischen "primaren pulmonalsklerose". Frankf Z Pathol 1934; 47: 100-108.

2. Heath D, Segel N, Bishop J. Pulmonary veno-occlusive disease. Circulation 1996; 34: 242-248.

3. Wagenvoort CA. Morphological changes in intrapulmonary veins. Hum Pathol 1970; 1: 205-213.

4. Wagenvoort CA. Pulmonary veno-occlusive disease. Entity or syndrome. Chest 1976; 69: 82-86.

5. Chawla SK, Kittle CF, Faber LP, Jensik RJ. Pulmonary venoocclusive disease. Ann Thorac Surg 1976; 22: 249253.

6. Edwards WD, Edwards JE. Clinical primary pulmonary hypertension: three different entities. Circulation 1977; 56: 884-888.

7. Sanderson JE, Spiro SG, Hendrey AT, Tumer-Warwick M. A case of pulmonary veno-occlusive disease responding to treatment with azathioprine. Thorax 1997; 32: 140148.

8. Haselton PS, Ironside JW, Whittaker JS, Kelly W, Ward C, Thompson GS. Pulmonary veno-occlusive disease: a report of four cases. Histopathology 1986; 10: 933-944.

9. Harris P, Heath D. Structural changes in the lung associated with pulmonary venous hypertension. In: The Human Pulmonary Circulation. Its Form and Function in Health and Disease. Churchill Livingstone, Edinburgh, London, Melbourne and New York. 3rd Ed., 1986, pp. 329-343.

10. Justo RN, Dare JA, Whight CM, Radford DJ. Pulmonary veno-occlusive disease: diagnosis during life in four patients. Arch Dis Child 1993; 68: 97-100.

11. Palevsky HI, Pietra GG, Fishman AP. Pulmonary venoocclusive disease and its response to vasodilator agents. Am Rev Respir Dis 1990; 142: 426-429. 
12. Schraufaegel DE, Sekosan M, McGee T, Thakkar MB Human alveolar capillaries undergo angiogenesis in pulmonary veno-occlusive disease. Eur Respir J 1996; 9: 346-350.

13. Rich S, Pietra CG, Kieras K, Hart K, Brundage BH. Primary pulmonary hypertension: radiographic and scintigraphic patterns of histologic subtypes. Ann Intern Med 1986; 105: 499-502.

14. Williams LM, Fussell S, Veith RW, Nelson S, Mason CM. Pulmonary veno-occlusive disease in an adult following bone marrow transplantation. Case report and review of the literature. Chest 1996; 109: 1388-1391.

15. Hackman CH, Madtes DK, Petersen FB, Clark JG. Pulmonary veno-occlusive disease following bone transplantation. Transplantation 1989; 47: 98-992.

16. Townsend JN, Roberts DH, Jones EL, Davies MK. Fatal pulmonary veno-occlusive disease after use of oral contraceptives. Am Heart J 1992; 124: 1643-1644.

17. Lombard CM, Churg A, Winokur S. Pulmonary venoocclusive disease after chemotherapy. Chest 1987; 92: 871-876.

18. Joselson R, Warnock M. Pulmonary veno-occlusive disease after chemotherapy. Human Pathol 1983; 14: 88-91.

19. Swift GL Gibbs A, Campbell IA, Wagenvoort CA, Tothill D. Pulmonary veno-occlusive disease and Hodgkins's lymphoma. Eur Respir J 1993; 6: 596-598.

20. Kramer MR, Estenne M, Berkman N, Antoine M, de Francquen P, Lipski A. Radiation-induced pulmonary veno-occlusive disease. Chest 1993; 104: 1282-1284.

21. Ruchelli ED, Noiadera G, Rutstein RM, Rudy B. Pulmonary veno-occlusive disease. Another vascular disorder associ ated with human immunodeficiency virus infection. Arch Pathol Lab Med 1994; 118: 664-666.

22. Voordes CG, Kuipers JRG, Elema JD. Familial pulmonary veno-occlusive disease: a case report. Thorax 1977; 32: 763-766.

23. Davies P, Reid L. Pulmonary veno-occlusive disease in siblings. Hum Pathol 1982; 13: 911-915.

24. Katzenstein M-LA, Askin FB. Pulmonary hypertension and other vascular diseases. In: Surgical Pathology of Non-Neoplastic Lung Disease. Philadelphia, USA, W.B. Saunders Co., 1990, pp. 432-467.
25. Heath D, Scon O, Lynch U. Pulmonary veno-occlusive disease. Thorax 1971; 26: 663-674.

26. Pietra GG, Edwards WD, Kay JM, et al. Histopathology of primary pulmonary hypertension. Circulation 1989; 80: 1198-1206.

27. Wagenvoort CA, Wagenvoort N, Takahashi T. Pulmonary veno-occlusive disease. Involvement of the pulmonary arteries and review of the literature. Hum Pathol 1985; 16: 1033-1041.

28. Wagenvoort CA, Wagenvoort N. The pathology of venoocclusive disease. Virchows Arch A Pathol Anat Histol 1974; 364: 69-79.

29. Thadani U, Burrow C, Whitaker W, Heath D. Pulmonary veno-occlusive disease. $Q J$ Med 1975; 173: 133-159.

30. Chazova I, Loyd DE, Zhdanov VS, Newman JH, Belenkov Y, Meyrick B. Pulmonary artery adventitial changes and venous involvement in primary pulmonary pertension. Am J Pathol 1995; 146: 389-397.

31. McDonell PJ, Summer WR, Hutchins GM. Pulmonary veno-occlusive disease. Morphological changes suggesting a viral cause. JAMA 1981; 246: 667-671.

32. Wagenvoort CA. Pathology of congestive pulmonary hypertension. Prog Respir Res 1975; 9: 195-202.

33. Berry DF, Buccigrossi D, Peabody J, Peterson L, Moser K. Pulmonary vascular occlusion and fibrosing mediastinitis. Chest 1986; 89: 296-301.

34. Meyrick B, Reid L. Ultrastructural features of the distended pulmonary arteria of the normal rat. Anat Rec 1979; 193: 73-97.

35. Meyrick B, Reid L. Hypoxia-induced structural changes in the media and adventitia of the rat hilar pulmonary artery and their regression. Am J Pathol 1980; 100: 151178.

36. Tozzi CA, Christiansen DL, Poiani GJ, Riley DJ. Excess collagen in hypertensive pulmonary arteries decreases vascular distensibility. Am J Respir Crit Care Med 1994; 149: 1317-1326.

37. Durmowicz AG, Parks WC, Hyde DM, Mecham RP, Stenmark KR. Persistence, re-expression, and induction of pulmonary arterial fibronectin, tropoelastin, and type I procollagen mRNA expression in neonatal hypexic pulmonary hypertension. Am J Pathol 1994; 145: 1411-1420. 